\section{CS-08 EFFECT OF ANTIMALARIALS OVER THE DIFFERENT DOMAINS OF THE DAMAGE INDEX IN LATIN AMERICAN SLE PATIENTS}

${ }^{1}$ Bernardo Pons-Estel*, ${ }^{2}$ Daniel Wojdyla, ${ }^{3}$ Graciela S Alarcón, ${ }^{1}$ Rosa María Serrano, ${ }^{1}$ Rosana Quintana, ${ }^{4}$ Manuel Ugarte-Gil, ${ }^{4}$ Victor Pimentel-Quiroz, ${ }^{5}$ Enrique R Soriano,

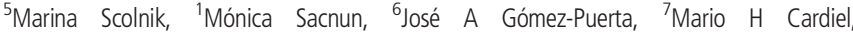
${ }^{8}$ Virginia Pascual-Ramos, ${ }^{9}$ Ignacio García de la Torre, ${ }^{10}$ Leonor A Barile, ${ }^{11}$ Luis H Silveira, ${ }^{12}$ Mary Carmen Amigo, ${ }^{13}$ María Josefina Sauza del Pozo, ${ }^{14}$ Marlene Guibert-Toledano, ${ }^{14} \mathrm{Gi}$ A Reyes, ${ }^{15}$ Antonio Iglesias Gamarra, ${ }^{6}$ Luis Alonso Gonzalez, ${ }^{16}$ Rosa Chacón-Díaz, ${ }^{17}$ María H Esteva Spinetti, ${ }^{4}$ Eduardo M Acevedo-Vásquez, ${ }^{4}$ José Alfaro-Lozano, ${ }^{18}$ María Inés Segami, ${ }^{19}$ Loreto Massardo, ${ }^{20}$ Oscar Neira, ${ }^{21}$ Emilia Sato, ${ }^{22}$ Eloisa Bonfa, ${ }^{23}$ Lilian Costallat, ${ }^{24}$ Ricardo Xavier, ${ }^{25}$ Fernando Cavalcanti, ${ }^{26}$ Nilizio A Da Silva, ${ }^{22}$ Eduardo Ferreira Borba, ${ }^{5}$ Luis J Catoggio, ${ }^{24}$ Joao C Tavares Brenol, ${ }^{27}$ Verónica Saurit, ${ }^{27}$ Francisco Caeiro, ${ }^{27}$ Alejandro Alvarellos, ${ }^{28}$ Judith Sarano, ${ }^{29}$ Mercedes Garcia, ${ }^{30}$ Laura Onetti, ${ }^{31}$ Cristina Drenkard, ${ }^{32}$ Guillermo Berbotto, ${ }^{33}$ Hugo R Scherbarth, ${ }^{34}$ Sergio Jacobelli, ${ }^{35}$ José F Molina, ${ }^{6}$ Gloria Vásquez, 'Guillermo J Pons-Estel. 'Hospital Provincial de Rosario, Argentina; ${ }^{2}$ GLADEL Consultant, Argentina; ${ }^{3}$ University of Alabama at Birmingham, USA; ${ }^{4}$ Hospital Nacional Guillermo Almenara Irigoyen, EsSalud, Perú; ${ }^{5}$ Hospital Italiano de Buenos Aires, Argentina; ${ }^{6}$ Universidad de Antioquia, Colombia; ${ }^{7}$ Centro de Investigación Clínica de Morelia SC, México; Instituto Nacional de Ciencias Médicas y Nutrición, México; ${ }^{9}$ Hospital General de Occidente, México; ${ }^{10}$ Hospital Ángeles del Pedregal, México; ${ }^{11}$ Instituto Nacional de Cardiología Ignacio Chávez, México; ${ }^{12}$ Centro Medico ABC, México; ${ }^{13}$ Instituto Mexicano de Seguro Social, Hospital de Especialidades $N^{\circ} 25$, México; ${ }^{14}$ Centro de Investigaciones Médico Quirúrgicas, Cuba; ${ }^{15}$ Universidad Nacional de Bogotá, Colombia; ${ }^{16} \mathrm{Hospital}$ Universitario de Caracas, Centro Nacional de Enfermedades Reumáticas, Venezuela; ${ }^{17}$ Hospital Central de San Cristóbal, Venezuela; ${ }^{18}$ Hospital Nacional Edgardo Rebagliatti Martins, ESSALUD, Perú; ${ }^{19}$ Universidad San Sebastián, Chile; ${ }^{20}$ Hospital del Salvador, Chile; ${ }^{21}$ Universidade Federal de Sao Paulo, Brasil; ${ }^{22}$ Faculdade de Medicina da Universidade de São Paulo, Brasil; ${ }^{23}$ Universidade Estadual da Campinas, Campinas, Brasil, ${ }^{24}$ Hospital da Clinicas da Porto Alegre, Brasil; ${ }^{25}$ Universidade Federal da Pernambuco, Brasil; ${ }^{26}$ Faculdade de Medicina, Universidade Federal de Goias, Brasil; ${ }^{27}$ Hospital Privado Universitario de Córdoba, Argentina; ${ }^{28}$ Instituto de Investigaciones Medicas Alfredo Lanari, Argentina; ${ }^{29}$ HIGA General San Martin La Plata, Argentina; ${ }^{30}$ Hospital Nacional de Clínicas, Argentina; ${ }^{31}$ Emory University School of Medicine, USA; ${ }^{32}$ Sanatorio Británico, Argentina; ${ }^{33} \mathrm{Hospital}$ Interzonal General de Agudos "Dr. Oscar Alende"; ${ }^{34}$ Argentina; Pontificia Universidad Católica de Chile, Chile; ${ }^{35}$ Centro Integral de Reumatología, Reumalab, Colombia

\subsection{6/lupus-2018-Ism.43}

Background We have previously shown that Latin American SLE patients treated with Antimalarials (AMs) have a 25\% lower risk of damage accrual than patients not receiving them. The present study was conducted to assess the effects of AMs over the 12 items of the SLICC Damage Index, (SDI).

Methods Patients with a recent SLE diagnosis ( $\leq 2$ years) from the GLADEL cohort were studied. End-point: Increase in the 12 items SDI since cohort entry. Independent (socio- demographic, clinical laboratory and treatment) variables were included. The effect of AMs as a time dependent variable on items of the SDI (adjusting for potential confounders) was examined with a multivariable Cox regression model. Multivariate models were developed for the most common SDI items.

Results Of the 1466 patients included in this analysis 1049 (72\%) received AMs during follow-up (as defined); median exposure time: 30 months (Q1-Q3: 11-57 months). Total damage accrual occurred in 665 (45\%) patients during a median follow up time of 24 months (Q1-Q3: 8-55) months. Within the 12 items of the SDI there were 301 integument, 208 renal, 149 neuropsychiatric, 98 musculoskeletal, 88 cardiovascular, 65 ocular, 43 pulmonary, 42 peripheral vascular, 33 gastrointestinal, 22 premature gonadal failure, 16 diabetes and 9 malignancy. After adjusting for potential confounders, at any time during follow-up a patient on AMs had a 35\% and 30\% lower risk of renal and neuropsychiatric damage accrual respectively than a patient not on AMs (adjusted HR 0.65, $95 \%$ CI 0.47 to 0.90 and HR 0.70 , 95\% CI 0.48 to 1.02 ). Such protective effect was not evident for integument, musculoskeletal and cardiovascular damage. Table 1.

Conclusions After adjustment for possible confounding factors related to AMs use and damage accrual, AMs were independently associated with a reduced risk of renal and neuropsychiatric damage accrual in this cohort.

Acknowledgements On behalf of the Grupo Latinoamericano de Estudio del Lupus (GLADEL).

\section{CS-09 CONTRACEPTIVE DOCUMENTATION IN SYSTEMIC LUPUS ERYTHEMATOSUS PATIENTS AT A SAFETY NET HOSPITAL}

Ola Azzouqah, Bonnie L Bermas*. Division of Rheumatic Diseases, UT Southwestern Medical Center, Dallas, Texas, USA

\subsection{6/lupus-2018-Ism.44}

Background Systemic Lupus Erythematosus (SLE) predominately affects reproductive aged women. Contraceptive counseling is an important quality indicator in SLE patient care. Here we evaluate current practice in the documentation of contraceptive use amongst reproductive aged women with SLE cared for at a large safety net hospital.

Abstract CS-08 Table 1 Multivariable Cox proportional hazard model: time-to-items damage accrual

\begin{tabular}{llll}
\hline Endpoint & Unadjusted & & Adjusted \\
\hline & $\mathrm{HR}^{1}(95 \% \mathrm{Cl})$ & $\mathrm{p}$-value & $\mathrm{HR}^{1}(95 \% \mathrm{Cl})$ \\
\hline Integument Damage & $0.987(0.763-1.277)$ & 0.9223 & $0.971(0.734-1.286)^{2}$ \\
Renal Damage & $0.516(0.385-0.692)$ & $<0.0001$ & $0.652(0.472-0.901)^{3}$ \\
Neuropsychiatric Damage & $0.651(0.458-0.925)$ & 0.0167 & $0.701(0.481-1.024)^{4}$ \\
Musculoskeletal Damage & $0.838(0.524-1.340)$ & 0.4612 & $0.909(0.561-1.473)^{5}$ \\
Cardiovascular Damage & $0.562(0.357-0.886)$ & 0.0130 & $0.690(0.430-1.107)^{6}$ \\
\hline
\end{tabular}

${ }^{1}$ Hazard ratio for any antimalarial vs no antimalarial in the previous month.

${ }^{2}$ Adjusted for integument domain SDI at entry, hypertension, malar rash, discoid rash, proteinuria/cilindruria, hematologic disorder, glucocorticoid pulse and SLEDAI at cohort entry.

${ }^{3}$ Adjusted for renal domain SDI at entry, age at diagnosis, socio-economic level, hypertension, proteinuria/cilindruria, immunosupressants and SLEDAI at cohort entry.

${ }^{4}$ Adjusted for neurologic domain SDI at entry, glucocorticoid pulse, NSAIDs and SLEDAI at cohort entry.

${ }^{5}$ Adjusted for musculoskeletal domain SDI at entry, gender, hypertension, discoid rash, oral/nasopharyngeal ulcerations, arthritis, neurologic disorder, glucocorticoids at cohort entry.

${ }^{6}$ Adjusted for cardiovascular domain SDI at entry, disease duration, hypertension and serositis at cohort entry. 